J. Dairy Sci. 95:3617-3628

http://dx.doi.org/10.3168/jds.2011-5297

(C) American Dairy Science Association ${ }^{\circledR}, 2012$.

\title{
Microstructural, textural, and sensory characteristics of probiotic yogurts fortified with sodium calcium caseinate or whey protein concentrate ${ }^{1}$
}

\author{
A. S. Akalın, ${ }^{2}$ G. Unal, ${ }^{\star}$ N. Dinkci, ${ }^{\star}$ and A. A. Hayaloglu† \\ *Department of Dairy Technology, Faculty of Agriculture, Ege University, 35100 Izmir, Turkey \\ †Department of Food Engineering, Engineering Faculty, Inonu University, 44280 Malatya, Turkey
}

\begin{abstract}
The influence of milk protein-based ingredients on the textural characteristics, sensory properties, and microstructure of probiotic yogurt during a refrigerated storage period of $28 \mathrm{~d}$ was studied. Milk was fortified with $2 \%$ (wt/vol) skim milk powder as control, $2 \%$ (wt/vol) sodium calcium caseinate $(\mathrm{SCaCN}), 2 \%$ (wt/ vol) whey protein concentrate (WPC) or a blend of $1 \%$ (wt/vol) SCaCNand 1\% (wt/vol) WPC. A commercial yogurt starter culture and Bifidobacterium lactis Bb12 as probiotic bacteria were used for the production. The fortification with $\mathrm{SCaCN}$ improved the firmness and adhesiveness. Higher values of viscosity were also obtained in probiotic yogurts with $\mathrm{SCaCN}$ during storage. However, WPC enhanced water-holding capacity more than the caseinate. Addition of $\mathrm{SCaCN}$ resulted in a coarse, smooth, and more compact protein network; however, WPC gave finer and bunched structures in the scanning electron microscopy micrographs. The use of $\mathrm{SCaCN}$ decreased texture scores in probiotic yogurt; probably due to the lower water-holding capacity and higher syneresis values in the caseinate-added yogurt sample. Therefore, the textural characteristics of probiotic yogurts improved depending on the ingredient variety.
\end{abstract}

Key words: probiotic yogurt, texture, sodium calcium caseinate, whey protein concentrate

\section{INTRODUCTION}

The textural and sensory characteristics of set-type yogurt are important quality parameters because they play an important role in consumers' acceptance of these products. Set yogurt with a relatively high level of syneresis is generally regarded as a low-quality product. Conventionally, syneresis is decreased by increasing the

Received December 23, 2011.

Accepted March 4, 2012.

${ }^{1}$ Part of this study was presented at the 7th NIZO Dairy Conference, Flavor and Texture Innovations in Dairy, September 21-23, 2011, Papendal, the Netherlands.

${ }^{2}$ Corresponding author: sibel.akalin@ege.edu.tr total solids of the yogurt mix to around $14 \%$ (wt/wt) with dry ingredients (Tamime and Deeth, 1980). In this respect, skim milk powder (SMP) is traditionally used for yogurt production. However, the availability and quality of other dairy ingredients make them attractive. Among these ingredients are whey protein concentrates (WPC) and caseinates that improve the texture and functional properties of the product (Remeuf et al., 2003).

Gel formation is one of the main properties in yogurt manufacture. Yogurt structure is the result of casein aggregation by $\mathrm{pH}$ dropping and disulfide bonding between $\kappa-\mathrm{CN}$ and denatured whey proteins. Protein fortification and heat treatment are the most important parameters that determine yogurt's textural properties. The effects of protein and TS content are sometimes difficult to study separately, as the 2 variables cannot be modified independently (Damin et al., 2009). Tamime and Robinson (1999) reported that according to the TS level, the greatest change in consistency was observed from 12 to $14 \mathrm{~g} / 100 \mathrm{~g}$ in yogurt. The nature and relative proportions of the different proteins in the DM significantly affect the texture of the final product. In the manufacture of set-type probiotic yogurt, the milk is fortified with dried dairy ingredients to achieve a final protein content of 40 to $50 \mathrm{~g} / \mathrm{kg}$ (Sodini et al., 2004, 2005). Previously, the effects of calcium caseinate, sodium caseinate (SC), and whey protein concentrate on the textural characteristics of yogurt or probiotic yogurt were studied (Martín-Diana et al., 2003; Sodini et al., 2005; Damin et al., 2009; Marafon et al., 2011a,b). However, no study has been done on the effect of sodium calcium caseinate $(\mathbf{S C a C N})$ on the quality of these products.

On the other hand, among the different process parameters, such as milk base composition, heat treatment, fermentation, and storage conditions, starter culture also plays a determinative role in gel structure formation. As probiotic bacteria grow slowly in milk because of the lack of proteolytic enzymes, they contribute poor sensory and textural characteristics to the product (Klaver et al., 1993; Dave and Shah, 1998a,b). Therefore, the practice is to blend these 
organisms with yogurt starter culture (Damin et al., 2008; Marafon et al., 2011a). The use of different dairy proteins will improve the structure of the product, though probiotic bacteria can cause some deterioration in textural quality of yogurt. Similarly, lower textural characteristics was found in a fermented milk containing yogurt culture plus Lactobacillus acidophilus LA5 and Lactobacillus rhamnosus LR35 than those found in the product containing the same bacteria except Lactobacillus bulgaricus LR35 (Sodini et al., 2002). Recently, Damin et al. (2008) reported that probiotic fermented milk prepared with Bifidobacterium animalis ssp. lactis, in coculture with Streptococcus thermophilus produces rheological characteristics similar to those of yogurt.

In addition, in the concept of functional foods, probiotics are added to yogurt in the prevention of disease and maintenance of health and well-being as a natural way of enhancing functionality. Within various probiotic microorganisms, Bifidobacterium lactis has been studied intensively and its beneficial roles for host health has been described (Janer et al., 2004; Shah, 2007). Bifidobacterium lactis is preferred for industrial production because of the oxygen and acid tolerance of $B$. lactis compared with other bifidobacteria species (Janer et al., 2004; Vasiljevic and Shah, 2008).

The aim of this study was to investigate the effects of SMP, WPC, SCaCN, or a blend of the last 2 on the microstructural, textural, and sensory characteristics of set-type probiotic yogurt containing B. lactis Bb12 throughout a $28-\mathrm{d}$ storage period at $4^{\circ} \mathrm{C}$.

\section{MATERIALS AND METHODS}

\section{Strains and Ingredients}

The commercial yogurt starter culture containing Strep. thermophilus and Lactobacillus delbrueckii ssp. bulgaricus (YC X-11) and B. animalis ssp. lactis (Bb12; Chr. Hansen A/S, Hørsholm, Denmark) were in freeze-dried direct vat set (DVS) form containing $10^{11}$ and $10^{10} \mathrm{cfu} / \mathrm{g}$, respectively.

Dairy ingredients used included SMP (Pinar Dairy Products, Izmir, Turkey), WPC (Oragel DY 101 XP), $\mathrm{SCaCN}$ (Armor Protéines, Saint-Brice-en-Coglès, France). The concentration of protein $( \pm \mathrm{SD})$ in the supplements was $33.7( \pm 0.79), 80( \pm 2.7)$, and 88.0 $( \pm 2.8) \mathrm{g} / 100 \mathrm{~g}$ for SMP, WPC, and SCaCN, respectively.

\section{Probiotic Yogurt Manufacture}

Set-type probiotic yogurt was prepared by using whole milk containing 3.65\% (wt/vol) milk fat (Pinar
Dairy Products) that was standardized with SMP to obtain $100 \mathrm{~g} / \mathrm{L}$ of nonfat milk solids. The milk was divided into 4 lots and supplemented with $2 \%$ SMP, WPC, SCaCN, and a blend of (1:1) WPC and SCaCN. After they were mixed properly, each milk base was heated at $85^{\circ} \mathrm{C}$ for $30 \mathrm{~min}$, by circulating in a hot water bath and cooled to $43^{\circ} \mathrm{C}$ in an ice bath. At this point, they were inoculated with both yogurt starter culture and B. lactis Bb12. All cultures were used according to the manufacturer's instructions. Yogurt starter culture was poured into $1 \mathrm{~L}$ of sterilized milk at $40^{\circ} \mathrm{C}$ and mixed thoroughly, and then $4 \mathrm{~mL}$ of the mix was added to $1 \mathrm{~L}$ of each milk base. Bifidobacterium lactis Bb12 was also added as $0.01 \%$. The mixtures were put into $200-\mathrm{mL}$ plastic containers and incubated at $40^{\circ} \mathrm{C}$ for about 4.5 $\mathrm{h}$ until pH 4.70 was reached. After fermentation, probiotic yogurt samples were cooled down and transferred to a refrigerator at $4^{\circ} \mathrm{C}$, then stored at this temperature over $28 \mathrm{~d}$ for the physicochemical, textural, and sensory analyses. The experiment was replicated 3 times on different days.

\section{Physicochemical Determinations}

The protein and TS content were determined according to the methods described in the Association of Official Analytical Chemists methods (AOAC, 1997). Fat contents were analyzed by the Gerber method (Renner, 1993). The $\mathrm{pH}$ of the yogurts was determined using a $\mathrm{pH}$ meter (model $\mathrm{pH}$ 211; Hanna Instruments, Woonsocket, RI). Titratable acidity was expressed as $\mathrm{g}$ of lactic acid/100 g after mixing $10 \mathrm{~g}$ of yogurt sample with $10 \mathrm{~mL}$ of hot distilled water and titrating with 0.1 $N \mathrm{NaOH}$ using $0.5 \%$ phenolphthalein indicator. Analysis was performed in triplicate after $24 \mathrm{~h}$ of product storage at $4^{\circ} \mathrm{C}$ (Turkish Yogurt Standard, 1989).

\section{Textural Properties}

Gel Firmness and Adhesiveness. The firmness and adhesiveness of probiotic yogurt samples were measured with a TA.XTplus texture analyzer (Stable Micro Systems, Vienna Court, UK) using a single-compression cycle test with a $5-\mathrm{kg}$ load cell. The probe used was a $35-\mathrm{mm}$ diameter aluminum cylinder. Pretest and test speed were fixed at $1 \mathrm{~mm} / \mathrm{s}$ and penetration depth was $30 \mathrm{~mm}$ (Bonczar et al., 2002; Sandoval-Castilla et al., 2004). According to Bourne (2002), firmness was defined as the force necessary to reach the maximum depth and adhesiveness was calculated as the negative force area of the cycle, representing the work necessary to pull the compressing plunger away from the sample. The test was carried out immediately after removing 
the samples from the refrigerator at $4^{\circ} \mathrm{C}$. Analyses were performed in duplicate for each trial.

Viscosity. The viscosity of the yogurts was measured, after stirring the product for $60 \mathrm{~s}$, using a Brookfield viscometer model DVI (Brookfield Engineering Laboratories Inc., Middleboro, MA) at $4^{\circ} \mathrm{C}$. Samples were tested using spindle no. 4 and data were taken as duplicate at a spindle rotation of $12 \mathrm{rpm}$ (Augustin et al., 2003; Donkor et al., 2007).

Syneresis Index. The syneresis index (g of drained whey $/ \mathrm{kg}$ of yogurt) was calculated according to the method described by Dannenberg and Kessler (1988). A portion of yogurt was removed with an ice cream scoop $(\mathrm{d}=45 \mathrm{~mm})$ and the surplus yogurt was removed with a knife so that a hemispherical sample with a volume of approximately $29 \mathrm{~mL}$ was obtained. It was placed with its flat side onto a test sieve (mesh width $0.5 \mathrm{~mm}$ ). The volume $(\mathrm{mL})$ of whey drained off was measured after 3 $\mathrm{h}$ at $10^{\circ} \mathrm{C}$. All the assays were performed in duplicate.

Water-Holding Capacity. The water-holding capacity (WHC) was determined with a modified procedure adapted from Remeuf et al. (2003). A sample of about $20 \mathrm{~g}$ of probiotic yogurt (PY) sample was centrifuged for $10 \mathrm{~min}$ at $5,000 \times g$ and $20^{\circ} \mathrm{C}$. The whey expelled (WE) was removed and weighed as grams. The WHC was defined as

$$
\mathrm{WHC}(\%)=\frac{(\mathrm{PY}-\mathrm{WE})}{(\mathrm{PY})} \times 100
$$

The measurement was carried out in duplicate.

Microstructure. Probiotic yogurts were prepared for microscope images after $24 \mathrm{~h}$ of product storage at $4^{\circ} \mathrm{C}$. Scanning electron microscopy was done, with the microstructure of the yogurt samples screened as described in Tamime et al. (1995) with some modifications. Yogurt sample $(0.3 \mathrm{~g})$ was mixed with an equal weight of $3 \%$ aqueous agar at $47^{\circ} \mathrm{C}$. Then, it was rested to solidify by cooling at room temperature $\left(21^{\circ} \mathrm{C}\right)$. After formation of a stabile gel, the samples were cut into specimens with $1 \times 1 \times 10 \mathrm{~mm}$ using a surgery lancet and immersed in $2.5 \%$ glutaraldehyde (prepared using a $1.0 \mathrm{M}$ phosphate buffer, $7.2 \mathrm{pH}$ ) solution overnight. The fixed specimens were washed 6 times $(1 \mathrm{~min}$ each time) using phosphate buffer ( $\mathrm{pH} 7.2)$ and then dehydrated in a graded ethanol series of 20,40,60, 80, 95 , and $100 \%$ for $30-\mathrm{min}$ intervals. The samples were critical-point dried using a critical point dryer (model K850: Quorum Technologies Ltd., Sussex, UK) and pieces reduced their height were mounted on the aluminum stubs. The mini-cubes were coated with a thin layer of gold-palladium in a sputter coater (model SCD
005; BalTec Inc., Balzers, Fürstentum, Liechtenstein) and transferred into a high-vacuum scanning electron microscope (LEO, EVO 40; Carl Zeiss SMT GmbH, Oberkochen, Germany). Measurements using the scanning electron microscope were carried out at $20 \mathrm{kV}$ and images were recorded at 5,000, 10,000, 20,000,30,000, and 40,000× magnifications. Only 20,000× magnification was shown for the present study.

\section{Sensory Characteristics}

Sensory evaluation of the samples was carried out according to the method modified from Turkish Yogurt Standard (1989) and Martín-Diana et al. (2003). The panel group consisted of 8 experienced academicians from the department of Dairy Technology (Ege University, Izmir, Turkey) who were familiar with attributes and scaling procedures of yogurt samples under study and who consume yogurts regularly in their diets. Sensory evaluation consisting of appearance, aroma, taste, texture, and overall acceptability were based on 5-point hedonic scales (1: dislike extremely; 5: like extremely). Panelists were also asked to note any perceived unnatural characteristics for taste and aroma (bitter, cooked, foreign, too high or low acid, or oxidized, among others), for texture (gel-like, grainy, coarse, too firm, or too weak, among others), and for appearance (whey-off or shrunken abnormal color, among others). Each sample was scored individually, and the samples were presented to the panelists in the individual plastic containers. Yogurts, coded with 3 digits, were randomly presented to the panel group at each session. Water was also presented to rinse their palate between samples. Panelists evaluated all of the samples after storage for 1,14 , and $28 \mathrm{~d}$ at $4^{\circ} \mathrm{C}$.

\section{Statistical Analyses}

The experiments including yogurt making was repeated 3 times. The data obtained were processed by one-way ANOVA using the general linear model (GLM) procedure of the SPSS software (version 11.05; SPSS Inc., Chicago, IL). The means were compared with Duncan multi-comparison test at the $P<0.05$ level.

\section{RESULTS AND DISCUSSION}

\section{Composition of Probiotic Yogurts}

The average composition $( \pm \mathrm{SD})$ of probiotic yogurts revealed that the fortification with dairy ingredients did not cause any significant difference $(P>0.05)$ in 
Table 1. Changes in $\mathrm{pH}$ and lactic acid concentration of control and experimental yogurts during storage

\begin{tabular}{|c|c|c|c|c|c|c|}
\hline \multirow[b]{2}{*}{ Item } & \multirow{2}{*}{$\begin{array}{l}\text { Type of } \\
\text { yogurt }^{1}\end{array}$} & \multicolumn{5}{|c|}{ Period of storage (d) } \\
\hline & & 1 & 7 & 14 & 21 & 28 \\
\hline \multirow[t]{3}{*}{$\mathrm{pH}$} & SMP & $4.44 \pm 0.01^{\mathrm{ab}, \mathrm{B}}$ & $4.47 \pm 0.03^{\mathrm{a}, \mathrm{A}}$ & $4.33 \pm 0.06^{\mathrm{d}, \mathrm{C}}$ & $4.42 \pm 0.05^{\mathrm{b}, \mathrm{B}}$ & $4.38 \pm 0.03^{\mathrm{c}, \mathrm{AB}}$ \\
\hline & WPC & $4.38 \pm 0.01^{\mathrm{ab}, \mathrm{C}}$ & $4.37 \pm 0.04^{\mathrm{bc}, \mathrm{B}}$ & $4.41 \pm 0.02^{\mathrm{a}, \mathrm{A}}$ & $4.34 \pm 0.02^{\mathrm{cd}, \mathrm{C}}$ & $4.32 \pm 0.04^{\mathrm{d}, \mathrm{B}}$ \\
\hline & WPC-SCaCN & $4.51 \pm 0.02^{\mathrm{a}, \mathrm{A}}$ & $4.47 \pm 0.00^{\mathrm{b}, \mathrm{A}}$ & $4.37 \pm 0.02^{\mathrm{d}, \mathrm{B}}$ & $4.42 \pm 0.01^{\mathrm{c}, \mathrm{B}}$ & $4.38 \pm 0.04^{\mathrm{d}, \mathrm{AE}}$ \\
\hline Lactic acid (g/100 g) & SMP & $1.24 \pm 0.06^{\mathrm{ab}, \mathrm{A}}$ & $1.27 \pm 0.02^{\mathrm{a}, \mathrm{B}}$ & $1.27 \pm 0.01^{\mathrm{a}, \mathrm{AB}}$ & $1.18 \pm 0.03^{\mathrm{b}, \mathrm{A}}$ & $1.30 \pm 0.04^{\mathrm{a}, \mathrm{A}}$ \\
\hline
\end{tabular}

\footnotetext{
${ }^{\mathrm{a}-\mathrm{d}}$ Means \pm standard deviations in the same row with different superscript lowercase letters are significantly different $(P<0.05)$

${ }^{\mathrm{A}-\mathrm{C}}$ Means \pm standard deviations in the same column with different superscript uppercase letters are significantly different $(P<0.05)$.

${ }^{1} \mathrm{SMP}=$ control probiotic yogurt containing skim milk powder; $\mathrm{SCaCN}=$ probiotic yogurt containing sodium calcium caseinate; $\mathrm{WPC}=$ probiotic yogurt containing whey protein concentrate; WPC-SCaCN = probiotic yogurt containing the blend of (1:1) WPC and SCaCN.
}

TS (between $14.73 \pm 0.05$ and $14.78 \pm 0.05 \%$ ) and fat (between $3.60 \pm 0.20$ and $3.80 \pm 0.20 \%$ ) contents among yogurt samples. Protein contents (between 5.17 \pm 0.07 and $5.52 \pm 0.17 \%)$ were also similar in the products fortified with different dairy proteins. Although control yogurt had a lower protein content $(4.23 \pm$ $0.05 \%)$ than the experimental samples $(P<0.05)$, no significant differences were found between the ratios of protein and TS $(P>0.05)$.

Table 1 shows the changes in $\mathrm{pH}$ and lactic acid contents of probiotic yogurts during $28 \mathrm{~d}$ of storage at $4^{\circ} \mathrm{C}$. Some fluctuations were observed for the $\mathrm{pH}$ values in all samples during storage. A similar observation was made by Ramchandran and Shah (2010) in probiotic yogurts. According to those authors, the ability of Strep. thermophilus to produce some basic metabolites during the later stage of storage could be a possible reason for the increase in $\mathrm{pH}$ observed during storage (Tinson et al., 1982).

In general, the $\mathrm{pH}$ was lower in yogurts fortified with WPC when compared with SCaCN. This may be due to the whey proteins, which generally have lower buffering capacity than casein (Walstra and Jenness, 1984). Therefore, lowering the concentration of casein would result in a reduction of buffering capacity as reported by Amatayakul et al. (2006). Marafon et al. (2011b) reported that partial replacement of SMP (45\%) with WPC and SC in probiotic yogurt did not affect the acidification profile showing similar $\mathrm{pH}$ values during 4 wk of storage.

In the samples, no significant changes were noted in the lactic acid percentages after 1, 21, and $28 \mathrm{~d}$ of storage, whereas the highest amount was produced in the sample with $\mathrm{SCaCN}$ at both $\mathrm{d} 7$ and $14(P<0.05)$. On the other hand, the yogurt sample fortified with the blend of WPC and SCaCN showed a significant increase in the lactic acid content at the end of storage in comparison to the first day $(P<0.05)$.

\section{Firmness, Adhesiveness, and Viscosity}

The firmness, adhesiveness, and viscosity of the probiotic yogurts are presented in Figures 1A, 1B, and 2 , respectively. A significant effect was observed for the firmness and viscosity of the yogurts fortified with the different dairy ingredients. The control probiotic yogurt (gray bar) was least firm $(P<0.05)$ probably due to the lowest protein content, which contributes to the firmness of the product (Figure 1A). The firmness of fermented milks containing probiotic bacteria is highly dependent on the culture composition, on the TS and protein content of the product, and also on the type of protein (Oliveira et al., 2001). Those authors reported that the nature of milk supplement significantly affected the firmness of the product, and also that the interaction between the ingredients used and the composition of the culture was significant. Sodini et al. (2004) reported that when the milk base was supplemented with proteins obtained from ultrafiltration, WPC, or caseinate, the firmness of the yogurts increased compared with a product fortified with SMP. This was due to the increase of the protein content in relation to the TS level.

The supplementation of SCaCN (black bar), WPC (striped bar), and the blend of WPC and $\mathrm{SCaCN}$ (white bar) increased the firmness of the products when compared with the addition of SMP $(P<0.05)$ (Figure $1 \mathrm{~A})$. The increase in firmness of the yogurt gel by addition of WPC can be explained by the fact that protein aggregates, formed by the interaction between casein micelles and denatured whey proteins via intermolecular disulfide bonds, appeared during the first steps of coagulation (Lucey et al., 1999). Bhullar et al. (2002) reported that the yogurt sample containing WPC was firmer than those containing SMP, depending on the increased water-binding capacities of denatured whey proteins in the sample. 

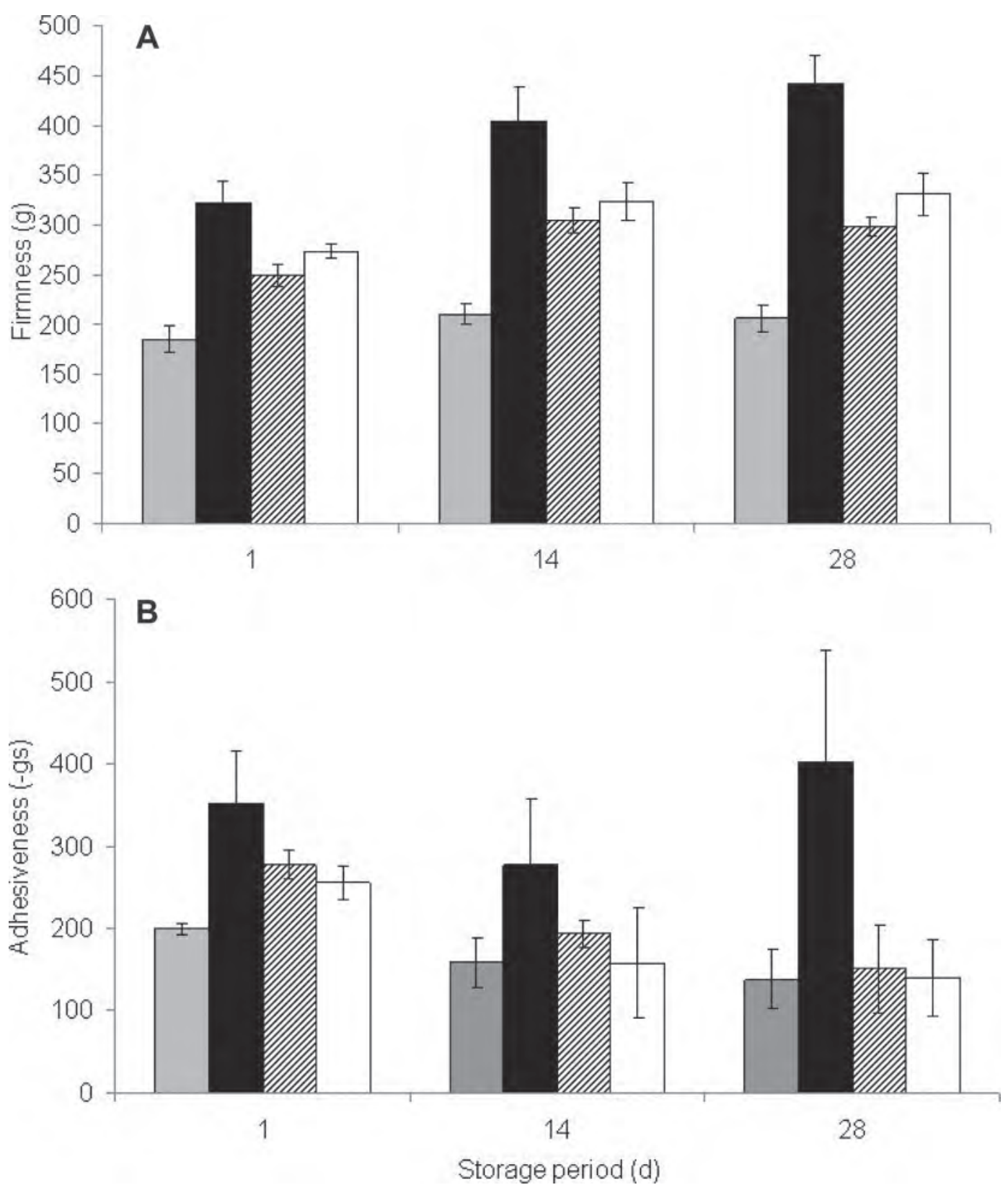

Figure 1. Firmness (A) and adhesiveness (B) in probiotic yogurts that were fortified with skim milk powder (gray; control), sodium calcium caseinate (SCaCN; black), whey protein concentrate (WPC; striped), or a 1:1 WPC-SCaCN blend (white) during storage. Error bars indicate standard deviations.

Fortification with SCaCN has been found to increase the firmness more than WPC in probiotic yogurts during storage $(P<0.05)$. These results are in agreement with the results of Guzmán-González et al. (1999) who reported that casein-based products tended to produce firmer gels with less syneresis than yogurts fortified with whey protein. Damin et al. (2009) also showed that yogurt made with milk supplemented with SC resulted in significant increase in firmness. According to the authors, when milk was supplemented with SC, a positive correlation was observed between protein levels and firmness, with a correlation coefficient value of 0.97 , whereas these values were 0.82 and 0.65 for supplementation with SMP and WPC, respectively.

Figure 1A shows that when milk was supplemented with SMP, the firmness did not change during storage $(P>0.05)$. On the contrary, firmness values of probiotic yogurts fortified with milk proteins significantly increased during storage $(P<0.05)$. This increase was observed at d 14 of storage and thereafter remained 


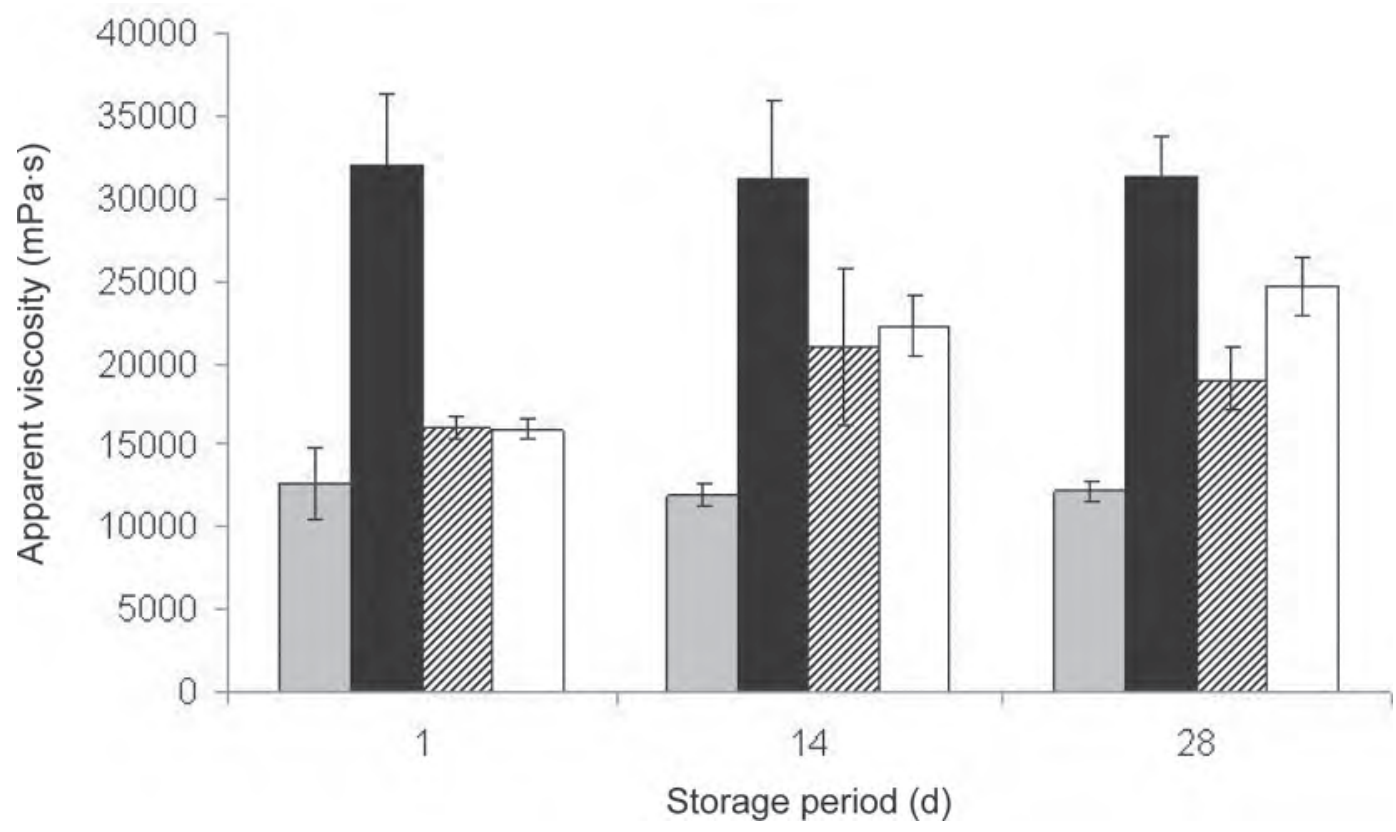

Figure 2. Apparent viscosity in probiotic yogurts that were fortified with skim milk powder (gray; control), sodium calcium caseinate (SCaCN; black), whey protein concentrate (WPC; striped), or a 1:1 WPC-SCaCN blend (white). Error bars indicate standard deviations.

constant in the samples with WPC and the WPC$\mathrm{SCaCN}$ blend, whereas a continuous increase was determined in yogurt samples with SCaCN. It has been well documented that the combination of calcium and $\mathrm{SC}$ caused inhibition of depletion flocculation in emulsions by binding of calcium to phosphoserine residues on the caseins (Dickinson et al., 2003; Radford et al., 2004). Therefore, the firmness of yogurt fortified with SCaCN may have been increased by the interaction between calcium and SC during storage.

The highest adhesiveness was also obtained by addition of SCaCN. The values of adhesiveness did not change in the samples fortified with $\mathrm{SCaCN}$ or WPC during storage, whereas they decreased in the samples with SMP and the WPC-SCaCN blend after the first week of storage (Figure 1B).

The viscosity changed in the same way as firmness. Probiotic yogurts fortified with SCaCN or WPC had higher viscosities than those fortified with SMP $(P<$ 0.05; Figure 2). Firmness and viscosity values decreased in the samples in the following order $\mathrm{SMP}<\mathrm{WPC}<$ the blend of WPC and $\mathrm{SCaCN}<\mathrm{SCaCN}$ at d $28(P<$ 0.05 ; Figures $1 \mathrm{~A}$ and 2).

Sodini et al. (2002) reported that the rheological parameters of probiotic fermented milks were influenced strongly by the starter culture and the milk base. Similarly, addition of casein or whey protein hydrolysates significantly affected the complex viscosity and the graininess in probiotic yogurts. However, the probiotic culture composition has a significant effect on these characteristics only depending on the type of hydrolysate (Sodini et al. 2005). Marafon et al. (2011b) reported that the rheological properties of probiotic yogurts were greatly enhanced when SMP (i.e., 45\%) was partially replaced with WPC and SC.

The effect of milk fortification with milk protein on increase in viscosity has been demonstrated in several studies (Sodini et al., 2004; Damin et al., 2009). Yogurt is suggested to have weak bonding, but SC supplementation tends to change the gel structure (Damin et al., 2009). As previously noted by Cho et al. (1999) and Guzmán-González et al. (2000), at similar protein levels, the addition of caseinate -instead of SMP in the milk base - strongly enhanced the viscosity of yogurt. Those authors reported that the higher viscosity values were obtained when the milk enriched with SMP instead of WPC. González-Martinéz et al. (2003) also reported that yogurts enriched with milk protein concentrate or SMP had higher viscosity and syneresis values compared with those supplemented with WPC.

In our study, probiotic yogurts fortified with WPC had higher viscosities than those enriched with SMP. The importance of added dairy protein to the milk base, especially those from whey, had different influences on the gel structure. The influence of WPC on the rheological properties of yogurt is dependent on the protein level of the product and heat treatment applied to the milk base containing WPC (Remeuf et al., 2003). In addition, in the studies of Cho et al. (1999), Guzmán-González et al. (2000), and González-Martinéz 
et al. (2003), the levels of WPC or SMP added were such that the final protein level was the same. The TS contents of experimental yogurts were adjusted to the same levels; however, protein levels were different. So, WPC was more effective in viscosity increase than SMP at the same TS level and the ratio of protein and TS. Similarly, the viscosity was the highest in yogurts made by incorporating WPC and the values gradually decreased in the samples containing SMP and no ingredient (Bhullar et al., 2002). In addition, WPC or WPC-SCaCN supplementation caused an increase in viscosity of probiotic yogurts during storage $(P<0.05$; Figure 2).

\section{Syneresis Index and WHC}

One of the most important structural characteristics of set-type yogurt is the strength of coagulum and its stability during storage. The average whey syneresis and WHC values in probiotic yogurts supplemented with various dairy ingredients are shown in Figures 3 and 4 , respectively. A significant decrease $(P<0.05)$ was observed for the syneresis indices of yogurts by the addition of dairy proteins when compared with SMP. Control yogurts exhibited the highest level of syneresis throughout the storage, whereas low-level syneresis was obtained by fortification with WPC at d 14 and $28(P$ $<0.05$; Figure 3).
Similar results on the decrease of whey separation by using WPC were also obtained by Guzmán-Gonzáles et al. (1999), Bhullar et al. (2002), and Remeuf et al. (2003). Puvanenthiran et al. (2002) suggested that an increase in the compactness of yogurt microstructure, as the casein-to-whey protein ratio was reduced, led to immobilization of a high level of free water.

Similarly, syneresis in yogurt samples supplemented with SMP and WPC decreased when the ratio of casein to whey protein was reduced from 4:1 to $1: 1$. It was reported that no syneresis was found in yogurt with a casein-to-whey protein ratio of 1:1 during $28 \mathrm{~d}$ of storage (Amatayakul et al., 2006). Reduction of whey syneresis corresponds to the improvement of WHC in whey protein, which increases with denaturation (Britten and Giroux, 2001). In addition, WPC or WPCSCaCN supplementation did not cause an increase in syneresis indices during the storage $(P>0.05)$ at a significant level (Figure 3).

Milk fortification had an effect on the WHC of yogurts, which varied from 68.78 to $43.22 \%$ (Figure 4). The higher WHC was obtained for yogurts made using milks fortified with WPC and then with blends of WPC and SCaCN, representing the values of 68.78 and $59.38 \%$, respectively, for the first day. The separate use of caseinate to fortify milk gave yogurts with lower WHC similar to the control samples.

It has been suggested that increasing the whey protein-to-casein ratio in the milk base improves the water-

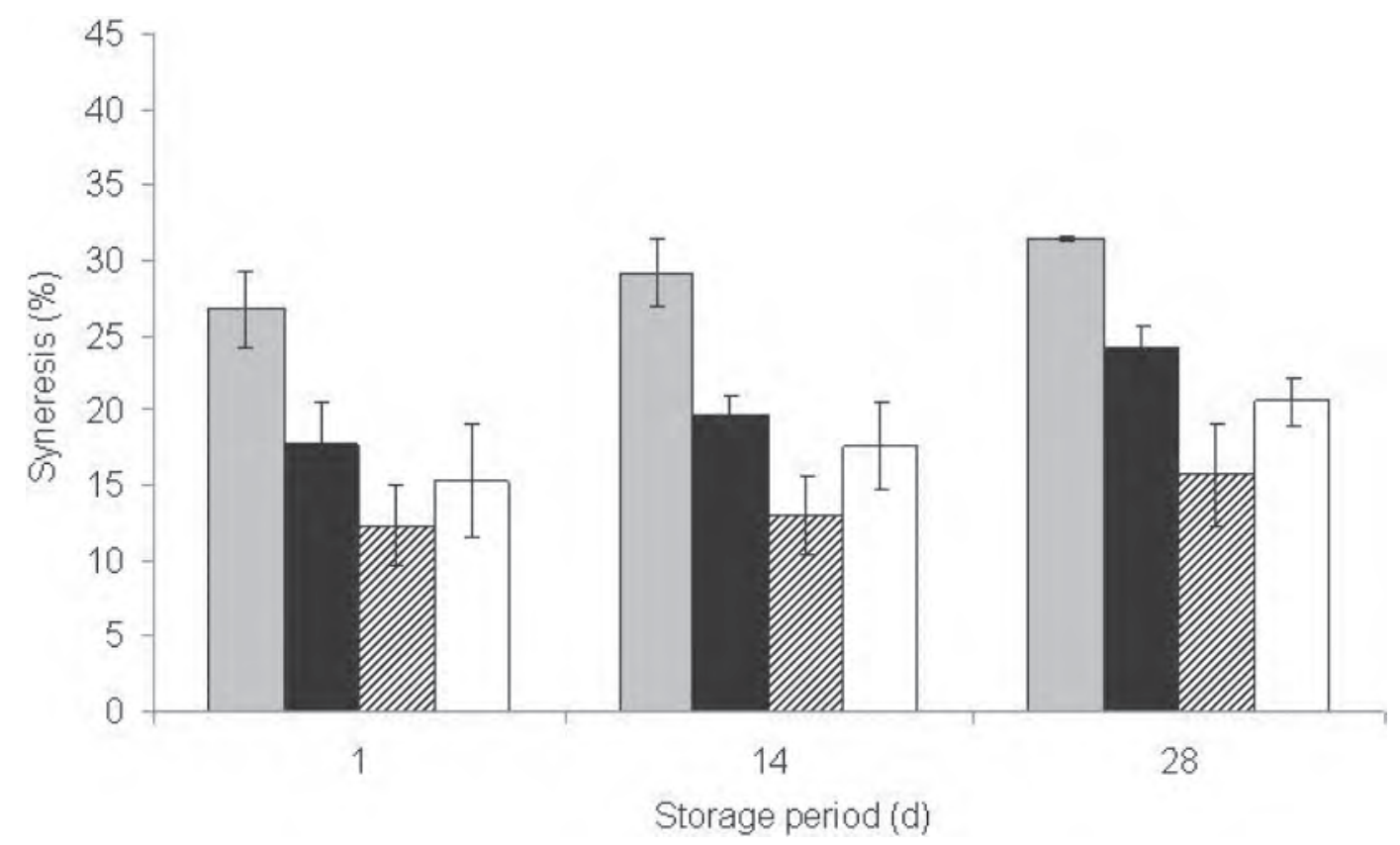

Figure 3. Syneresis values in probiotic yogurts that were fortified with skim milk powder (gray; control), sodium calcium caseinate (SCaCN; black), whey protein concentrate (WPC; striped), or a 1:1 WPC-SCaCN blend (white). Error bars indicate standard deviations. 


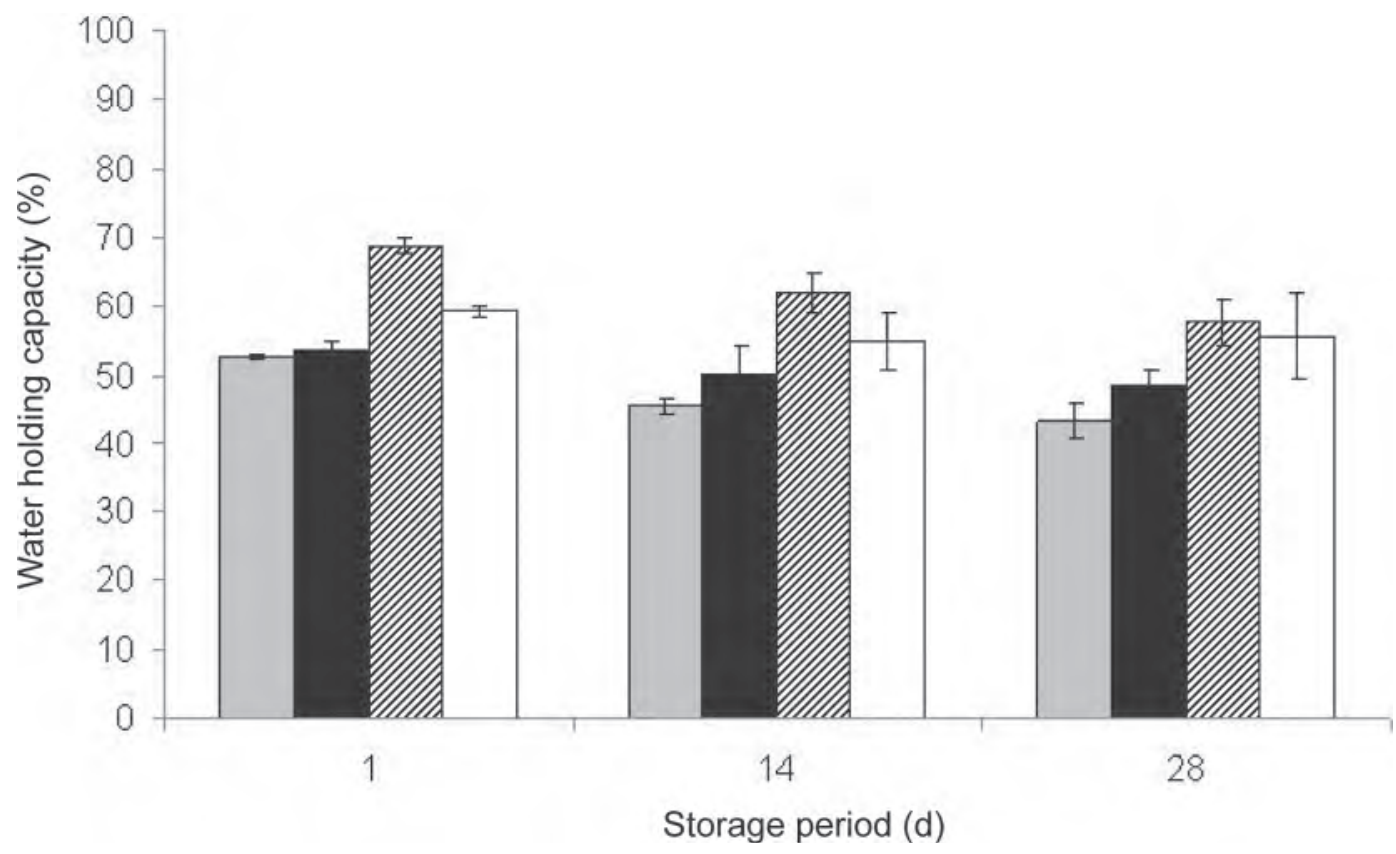

Figure 4. Water-holding capacity values in probiotic yogurts that were fortified with skim milk powder (gray; control), sodium calcium caseinate (SCaCN; black), whey protein concentrate (WPC; striped), or a 1:1 WPC-SCaCN blend (white). Error bars indicate standard deviations.

binding capacity of the yogurt coagulum (Sodini et al., 2004). This was also confirmed by Guzmán-González et al. $(1999,2000)$, who found that the WHC of yogurt was increased by $77 \%$ when partially replacing skim milk concentrate with WPC, whereas the increase was only $2 \%$, when caseinate was used instead of WPC. High WHC in WPC-containing samples could be related to higher solvation of the micellar system and to a more branched yogurt microstructure, less susceptible to losing water when submitted to centrifugal forces (Remeuf et al., 2003).

On the other hand, WHC values of probiotic yogurts fortified with SCaCN or the blend of WPC and SCaCN did not change during storage, but a significant decrease was obtained in WPC-containing samples, which could arise from the looser bonds between $\mathrm{H}_{2} \mathrm{O}$ molecules and whey protein; WHC can be affected by this biochemical event with the decrease in $\mathrm{pH}$ to the end of storage.

\section{Microstructure}

The microstructure of the samples was screened by the scanning electron microscopy technique at different magnifications. Scanning electron microscope images of the probiotic yogurt samples differed because of the addition of dairy proteins. Addition of these proteins also increased the levels of TS and proteins; these increases caused the formation of a gel network by cross-linking during the fermentation of the milk. Figure 5 shows the images of the samples fortified with skim milk powder (A), SCaCN (B), WPC (C), and the mixture of WPC and $\mathrm{SCaCN}(\mathrm{D})$. The microstructure of the probiotic yogurt made using skim milk powder gave totally different images in comparison to the other images, as shown in Figure 5. Large pores were observed in the samples made using skim milk powder, as reported by other workers (Damin et al., 2009; Matumoto-Pintro et al. 2011). Marafon et al. (2011b) also reported that the pore sizes in the micrographs obtained from the nonfortified probiotic yogurt at d 1 were larger than those from the fortified yogurt by partially replacing SMP (45\%) with WPC and SC.

Among the protein aggregates, there were some openings and fat globules; fewer pores were also screened, especially in B and D samples (Figure 5). The microstructure of the samples made using $\mathrm{SCaCN}$ caused a coarse and compact structure in comparison to the samples fortified with WPC, possibly increasing the firmness. Microstructure of the samples made using WPC (Figure 5C) was less dense and compact, probably due to the interaction between denatured $\beta-\mathrm{LG}$ and caseins. Use of the WPC caused a clearly different microstructure in the samples, reflecting some fine cross-linking among globular proteins and caseins. The looser and porous structure as well as cross-linking capacity of WPC-added products may improve the WHC and reduce the syneresis indices by increasing the degree of bridging between protein particles. Similar 

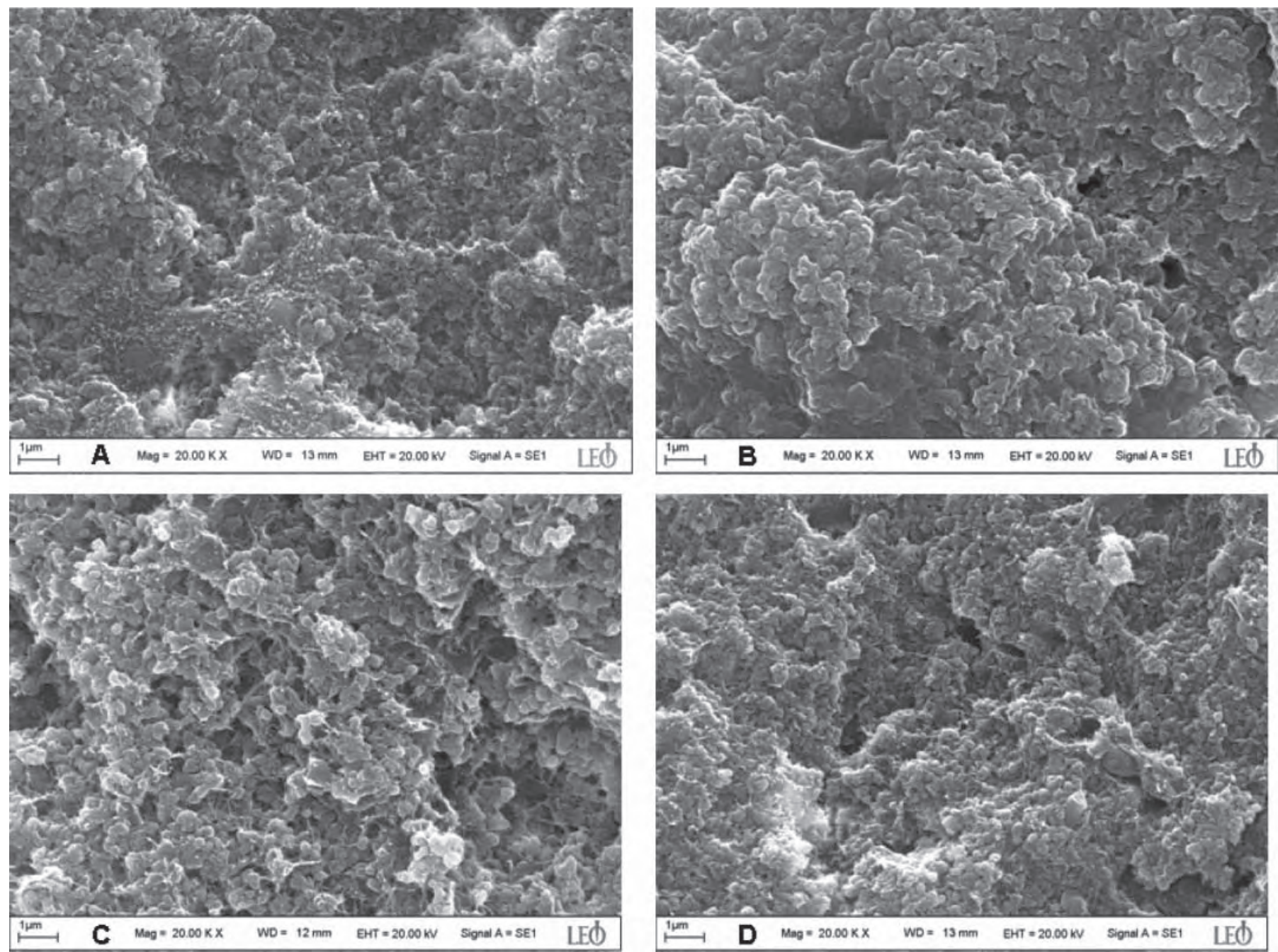

Figure 5. Scanning electron microscopy of yogurts that were fortified with skim milk powder (A; control), sodium calcium caseinate (SCaCN B), whey protein concentrate (WPC; C), or a 1:1 WPC-SCaCN blend (D).

microstructures were obtained in the yogurt samples by Puvanenthiran et al. (2002), who observed that as the ratio of whey protein increased, the network became finer, the size of the aggregates became smaller, the network of cross-links denser, and the pores smaller. The mixture of WPC and SCaCN gave similar images produced by the probiotic yogurt fortified with $\mathrm{SCaCN}$; however, some holes and more cross-linked structures appeared. The use of some types of caseinate and whey protein concentrate has effects to some extent on the microstructure of the yogurt samples.

\section{Sensory Evaluation}

Sensory attributes were evaluated as appearance, aroma, taste, texture, and overall acceptability. Texture was evaluated by both visual controls with a spoon or mouth feel. The results for the experimental yogurts are given in Figure 6A (d 1), B (d 14), and C (d 28).

No significant differences were noted among samples in terms of appearance, aroma, taste, and overall acceptability during storage $(P>0.05)$. In general, substitution with probiotic ingredients has a greater influence on flavor and aroma. The metabolism of the probiotic culture can result in the production of components that may contribute negatively to the aroma and taste of the product (Cruz et al. 2010). The sensory evaluation scores on aroma (between 5.00 and 4.63) and taste (between 4.81 and 4.19) in probiotic yogurts were found to be at acceptable values during storage. Texture scores of the samples revealed significant differences among the samples and the sample fortified with $\mathrm{SCaCN}$ received lower scores for texture with spoon at the beginning of storage $(P<0.05$; Figure $6 \mathrm{~A})$. However, the 

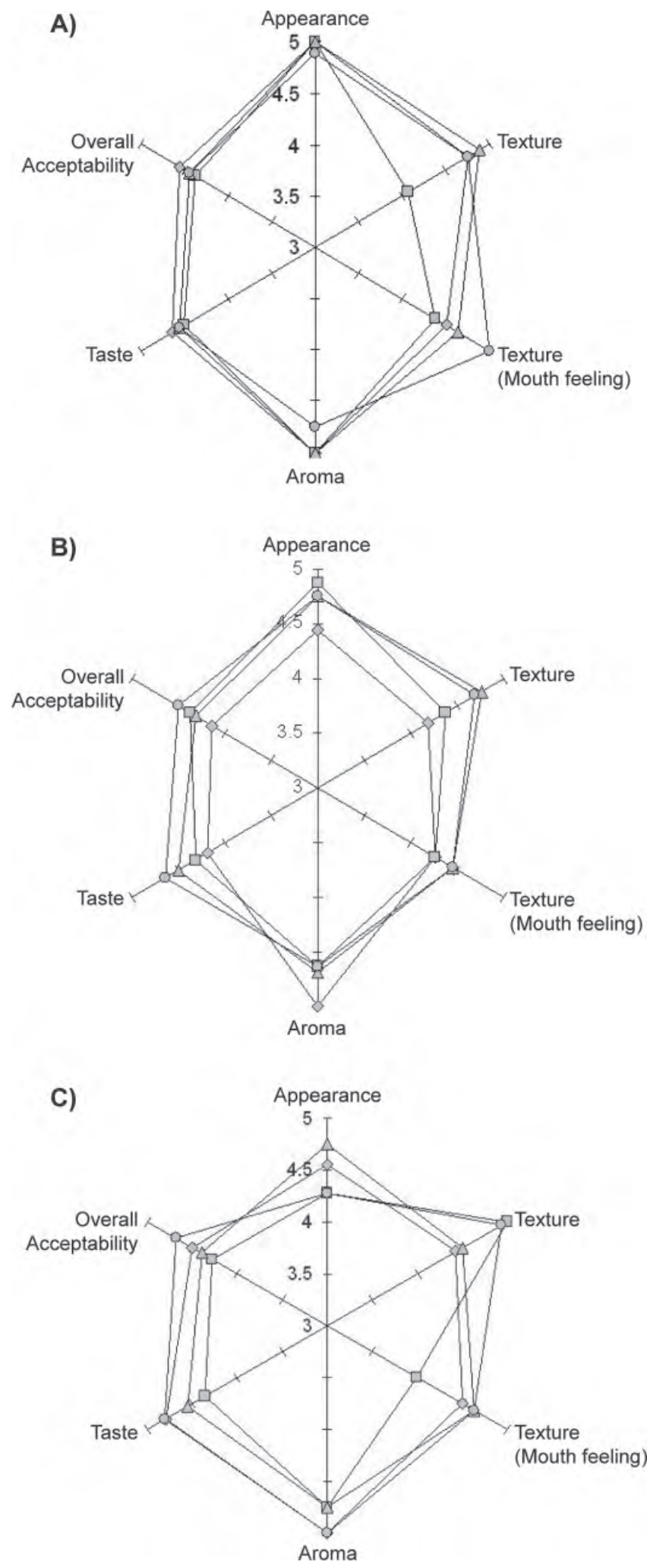

Figure 6. Sensory scores of A) 1-d-old yogurts, B) 14-d-old yogurts, and C) 28-d-old yogurts; $\diamond=$ control yogurt sample containing skim milk powder; $\square=$ yogurt sample containing sodium calcium caseinate $(\mathrm{SCaCN}) ; \Delta=$ yogurt sample containing whey protein concentrate (WPC); $\bigcirc=$ yogurt sample containing a 1:1 WPC-SCaCN blend. values increased in that product during storage $(P<$ 0.05 ) and the yogurt with $\mathrm{SCaCN}$, together with the WPC-SCaCN blend sample, had the highest scores for this sensory characteristic at the end of storage $(P<$ 0.05 ; Figure $1 \mathrm{C}$ ). The increase in texture score depends on the $\mathrm{WHC}$ of $\mathrm{SCaCN}$-added products that remained stable during storage. In addition, the increase in the firmness of yogurt fortified with SCaCN throughout storage may have been improved texture scores. Marafon et al. (2011b) also reported that the supplementation of the milk base with milk proteins increased the consistency of the probiotic yogurt in terms of sensory attributes; however, the values decreased during 28-d storage.

The expert panel members stated that clear differences also were noticeable for mouth feel texture on $\mathrm{d}$ 1 and 28 of storage and $\mathrm{SCaCN}$-added yogurts received lower scores on both days $(P<0.05)$. The panelists implied that a coarse texture was felt in the samples with SCaCN. Similarly, yogurt enriched with SC at a whey protein-to-casein ratio of 0.16 exhibited a coarse texture when assessed visually with a spoon, whereas yogurt made from milk fortified at the whey proteinto-casein ratio of 0.22 showed smooth textures (Sodini et al., 2004).

The effect of storage time on the appearance of the probiotic yogurts was found to be significant and the scores decreased $(P<0.05)$ in all samples during storage, except the product containing WPC. This probably resulted from the smooth and glossy appearance of WPC-added samples and the ability of WPC to decrease syneresis in yogurt. Marafon et al. (2011b) reported that the scores on appearance in probiotic yogurts produced by partial replacement of SMP (45\%) with WPC and SC decreased after $28 \mathrm{~d}$ of storage. Similarly, sensory evaluation scores on the flavor, the body and texture, and the color and appearance of the yogurts fortified with casein hydrolysates decreased by storage time (Zhao et al., 2006).

\section{CONCLUSIONS}

Fortification of milk with SCaCN, WPC, or the blend of WPC and $\mathrm{SCaCN}$ improved the textural, microstructural, and some sensorial characteristics of probiotic yogurt compared with fortification with SMP. Probiotic yogurt from milk fortified with SCaCN showed much higher values of firmness and viscosities than yogurt from SMP- or WPC-fortified milk. Although supplementation with WPC caused a softer structure in probiotic yogurt, the samples with WPC showed higher WHC and suffered less syneresis than the other yogurts. Addition of $\mathrm{SCaCN}$ resulted in a coarse, smooth, and more compact protein network in 
the scanning electron microscope micrographs. Also, WPC caused some interactions between globular proteins and caseins, so finer and bunched structures were obtained by using the WPC in the manufacture of probiotic yogurt. No significant differences were noted between the experimental yogurts in terms of sensory attributes except texture. The use of $\mathrm{SCaCN}$ or the blend of WPC and SCaCN increased the texture scores during storage.

\section{ACKNOWLEDGMENTS}

The authors thank the Turkish Scientific and Research Council (TUBITTAK, Ankara, Turkey) for financial support for this research (project no: TOVAG 106 O 122).

\section{REFERENCES}

Amatayakul, T., A. L. Halmos, F. Sherkat, and N. P. Shah. 2006. Physical characteristics of yoghurts made using exopolysaccharideproducing starter cultures and varying casein to whey protein ratios. Int. Dairy J. 16:40-51.

AOAC. 1997. Official Methods of Analysis. 15th ed. Association of Official Analytical Chemists, Washington, DC.

Augustin, M. A., L. J. Cheng, O. Glagovskaia, P. T. Clarke, and A. Lawrence. 2003. Use of blends of skim milk and sweet whey protein concentrates in reconstituted yogurt. Aust. J. Dairy Technol. 58:30-35.

Bhullar, Y. S., M. A. Uddin, and N. P. Shah. 2002. Effects of ingredients supplementation on textural characteristics and microstructure of yoghurt. Milchwissenschaft 57:328-332.

Bonczar, G., M. Wszolek, and A. Siuta. 2002. The effects of certain factors on the properties of yoghurt made from ewe's milk. Food Chem. 79:85-91.

Bourne, M. 2002. Food Texture and Viscosity: Concept and Measurement. 2nd ed. Academic Press, New York, NY.

Britten, M., and H. J. Giroux. 2001. Acid-induced gelation of whey protein polymers: Effects of $\mathrm{pH}$ and calcium concentration during polymerization. Food Hydrocoll. 15:609-617.

Cho, Y. H., J. A. Lucey, and H. Singh. 1999. Rheological properties of acid milk gels as affected by the nature of the fat globule surface material and heat treatment of milk. Int. Dairy J. 9:537-545.

Cruz, A. G., R. S. Cadena, E. H. M. Walter, A. M. Mortazavian, D. Granato, J. A. F. Faria, and H. M. A. Bolini. 2010. Sensory analysis: Relevance for prebiotic, probiotic, and synbiotic product development. Compr. Rev. Food Sci. Food Saf. 9:358-373.

Damin, M. R., M. R. Alcântara, A. P. Nunes, and M. N. Oliveira. 2009. Effects of milk supplementation with skim milk powder, whey protein concentrate and sodium caseinate on acidification kinetics, rheological properties and structure of nonfat stirred yogurt. Lebenson. Wiss. Technol. 42:1744-1750.

Damin, M. R., E. Minowa, M. R. Alcântara, and M. N. Oliveira. 2008. Effect of cold storage on culture viability and some rheological properties of fermented milk prepared with yogurt and probiotic bacteria. J. Texture Stud. 39:40-55.

Dannenberg, F., and H. G. Kessler. 1988. Effect of denaturation of $\beta$-lactoglobulin on texture properties of set-type nonfat yoghurt. 1. Syneresis. Milchwissenschaft 43:632-635.

Dave, R. I., and N. P. Shah. 1998a. Ingredient supplementation effects on viability of probiotic bacteria in yogurt. J. Dairy Sci. $81: 2804-2816$.

Dave, R. I., and N. P. Shah. 1998b. The influence of ingredient supplementation on the textural characteristics of yogurt. Aust. J. Dairy Technol. 53:180-184.
Dickinson, E., S. J. Radford, and M. Golding. 2003. Stability and rheology of emulsions containing sodium caseinate: Combined effects of ionic calcium and non-ionic surfactant. Food Hydrocoll. $17: 211-220$.

Donkor, O. N., S. L. I. Nilmini, P. Stolic, T. Vasiljevic, and N. P Shah. 2007. Survival and activity of selected probiotic organisms in set-type yoghurt during cold storage. Int. Dairy J. 17:657-665.

González-Martinéz, C., M. Becerra, M. Cháfer, A. Albors, J. M. Carot, and A. Chiralt. 2003. Influence of substituting milk powder for whey powder on yoghurt quality. Trends Food Sci. Technol. $13: 334-340$.

Guzmán-González, M., F. Morais, and L. Amigo. 2000. Influence of skimmed milk concentrate replacement by dry dairy products in a low-fat set-type yoghurt model system. Use of caseinates, co-precipitate and blended dairy powders. J. Sci. Food Agric. 80:433-438.

Guzmán-González, M., F. Morais, M. Ramos, and L. Amigo. 1999. Influence of skimmed milk concentrate replacement by dry dairy products in a low fat set-type yoghurt model system. I: Use of whey protein concentrates, milk protein concentrates and skimmed milk powder. J. Sci. Food Agric. 79:1117-1122.

Janer, C., C. Peláez, and T. Requena. 2004. Caseinomacropeptide and whey protein concentrate enhance Bifidobacterium lactis growth in milk. Food Chem. 86:263-267.

Klaver, F. A. M., F. Kingma, and A. H. Weerkamp. 1993. Growth and survival of bifidobacteria in milk. Neth. Milk Dairy J. 47:151-164.

Lucey, J. A., P. A. Munro, and H. Singh. 1999. Effects of heat treatment and whey protein addition on the rheological properties and structure of acid skim milk gels. Int. Dairy J. 9:275-279.

Marafon, A. P., A. Sumi, M. R. Alcântara, A. Y. Tamime, and M. N. Oliveira. 2011a. Optimization of the rheological properties of probiotic yoghurts supplemented with milk proteins. Lebenson. Wiss. Technol. 44:511-519.

Marafon, A. P., A. Sumi, D. Granato, M. R. Alcântara, A. Y. Tamime, and M. N. Oliveira. 2011b. Effects of partially replacing skimmed milk powder with dairy ingredients on rheology, sensory profiling, and microstructure of probiotic stirred-type yogurt during cold storage. J. Dairy Sci. 94:5330-5340.

Martín-Diana, A. B., C. Janer, C. Peláez, and T. Requena. 2003. Development of a fermented goat's milk containing probiotic bacteria. Int. Dairy J. 13:827-833.

Matumoto-Pintro, P. T., L. Rabiey, G. Robitaille, and M. Britten. 2011. Use of modified whey protein in yoghurt formulations. Int. Dairy J. 21:21-26.

Oliveira, M. N., I. Sodini, F. Remeuf, and G. Corrieu. 2001. Effect of milk supplementation and culture composition on acidification, textural properties, and microbiological stability of fermented milks containing probiotic bacteria. Int. Dairy J. 11:935-942.

Puvanenthiran, A., R. P. W. Williams, and M. A. Augustin. 2002. Structure and visco-elastic properties of set yoghurt with altered casein to whey protein ratios. Int. Dairy J. 12:383-391.

Radford, S. J., E. Dickinson, and M. Golding. 2004. Stability and rheology of emulsions containing sodium caseinate: Combined effects of ionic calcium and alcohol. J. Colloid Interface Sci. 274:673-686.

Ramchandran, L., and N. P. Shah. 2010. Characterization of functional, biochemical and textural properties of synbiotic low-fat yoghurts during refrigerated storage. Lebenson. Wiss. Technol. $43: 819-827$.

Remeuf, F., S. Mohammed, I. Sodini, and J. P. Tissier. 2003. Preliminary observations on the effects of milk fortification and heating on microstructure and physical properties of stirred yogurt. Int. Dairy J. 13:773-782.

Renner, E. 1993. Milchpractikum. Justus-Liebig-Universität, Giessen, Germany.

Sandoval-Castilla, O., C. Lobato-Calleros, E. Aguirre-Mandujano, and E. J. Vernon-Carter. 2004. Microstructure and texture of yogurt as influenced by fat replacers. Int. Dairy J. 14:151-159.

Shah, N. P. 2007. Functional cultures and health benefits. Int. Dairy J. $17: 1262-1277$.

Sodini, I., A. Lucas, M. N. Oliveira, F. Remeuf, and G. Corrieu. 2002. Effect of milk base and starter culture on acidification, texture, 
and probiotic cell counts in fermented milk processing. J. Dairy Sci. 85:2479-2488.

Sodini, I., J. Montella, and P. S. Tong. 2005. Physical properties of yoghurt fortified with various commercial whey protein concentrates. J. Sci. Food Agric. 85:853-859.

Sodini, I., F. Remeuf, S. Haddad, and G. Corrieu. 2004. The relative effect of milk base, starter and process on yoghurt texture: A review. Crit. Rev. Food Sci. Nutr. 44:113-137.

Tamime, A. Y., and H. C. Deeth. 1980. Yogurt: Technology and biochemistry. J. Food Prot. 43:939-977.

Tamime, A. Y., M. Kaláb, D. D. Muir, and E. Barrantes. 1995. The microstructure of set-style, natural yoghurt made by substituting microparticulate whey protein for milk fat. Int. J. Dairy Technol. 48:107-111.
Tamime, A. Y., and R. K. Robinson. 1999. Yoghurt: Science and Technology. 2nd ed. CRC Press, Boca Raton, FL.

Tinson, W., M. C. Broome, A. J. Hillier, and G. R. Jago. 1982. Metabolism of Streptococcus thermophilus. 2. Production of $\mathrm{CO}_{2}$ and $\mathrm{NH}_{3}$ from urea. Aust. J. Dairy Technol. 37:14-16.

Turkish Yogurt Standard. 1989. TSE 1330. Turkish Standards Institute, Ankara, Turkey.

Vasiljevic, T., and N. P. Shah. 2008. Probiotics-From Metchnikoff to bioactives. Int. Dairy J. 18:714-728.

Walstra, P., and R. Jenness. 1984. Dairy Chemistry and Physics. Wiley, New York, NY.

Zhao, Q. Z., J. S. Wang, M. M. Zhao, Y. M. Jiang, and C. Chun. 2006. Effect of casein hydrolysates on yoghurt fermentation and texture properties during storage. Food Technol. Biotechnol. 44:429-434. 